\title{
KISSINGER KINETIC ANALYSIS OF DATA OBTAINED UNDER DIFFERENT HEATING SCHEDULES
}

\author{
P.E. Sánchez-Jiménez, J.M. Criado, L.A. Pérez-Maqueda* \\ Instituto de Ciencia de Materiales de Sevilla (CSIC-Universidad de Sevilla). \\ C. Americo Vespucio 49,41092 Sevilla, Spain,maqueda@cica.es
}

\begin{abstract}
The dynamic heating rate method developed by TA Instruments $\left(H i-\operatorname{Res}^{\mathrm{TM}}\right)$ is a kind of sample controlled thermal analysis in which a linear relationship between the logarithm of the heating rate and the rate of weight change is imposed. It is shown in this paper that the reacted fraction at the maximum reaction rate strongly depends on the parameters selected for the Hi-Res heating algorithm, what invalidates the use of the Kissinger method for analysing Hi-Res data unless that the reaction fits a first order kinetic law. Only in this latter case, it has been demonstrated that it is not required that a constant value of the reacted fraction at the maximum reaction rate is fulfilled for determining the activation energy from the Kissinger method. In such a case the Kissinger plot gives the real activation energy, independently of both the heating schedule used and the value of the reacted fraction, $\alpha_{m}$, at the maximum.
\end{abstract}

*corresponding author: maqueda@cica.es 


\section{Introduction}

In Sample Controlled Thermal Analysis (SCTA) methods, the evolution of the temperature is determined by the reaction progress through a feedback system [1-3]. Thus, unlike conventional methods were the temperature follows a predefined function of time, usually linear increase with time or isothermal, in the SCTA method the evolution of temperature is not predetermined because it depends on the evolution of the sample with the temperature. The SCTA methods require monitoring the evolution of the sample. For thermogravimetry, the weight loss or weight gain (TG signal) is a direct measure of the reacted fraction, while the DTG signal gives a direct measure of the reaction rate $[4,5]$. The most conventional SCTA method is the Constant Rate Thermal Analysis (CRTA) where the reaction rate is maintained constant at a value previously selected. The kinetic analysis of solid state reactions by means of CRTA has been extensively described in literature [6-12]. A different approach to SCTA is the High Resolution TGA (Hi-Res) also known as dynamic heating rate method. The Hi-Res is a combined rate and temperature controlled thermal analysis method where neither the temperature nor the reaction rate follows a predefined function, but the heating rate is influenced by the evolution of the reaction rate through an algorithm. Thus the heating rate varies in a range from a maximum to minimum selected values depending on the evolution of the reaction rate $[2,13,14]$. It has been claim that this method provides a better resolution power for overlapping processes as compared with conventional linear heating rate TG [2]. As in dynamic heating rate, neither the evolution of the reaction rate nor the evolution of temperature is known, it makes useless the conventional kinetic analysis methods proposed in literature for experimental data obtained under a constant heating rate. The Kissinger method [15] is extensively used in literature for determining the activation energy of experimental data obtained under linear heating rate conditions. Thus, more than 2000 citations can be found for the original publication, many of them in this journal [16-25]. Recently, the Kissinger method has been extended [26-30] to the kinetic analysis of Hi-Res data. The scope of this paper is to carry out a critical study of the generalization of the Kissinger method for determining the activation energy 
from data obtained under heating schedules different than those assumed in the development of this method.

\section{Theoretical}

For solid state transformations, the reaction rate can be written in the form:

$$
\frac{d \alpha}{d t}=A \cdot e^{-E / R T} f(\alpha)
$$

being $\alpha$ the reacted fraction, $\mathrm{A}$ the preexponential factor of Arrhenius, $\mathrm{E}$ the activation energy, $\mathrm{T}$ the absolute temperature, $\mathrm{R}$ is the gas constant and $\mathrm{f}(\alpha)$ is the reaction kinetic model $[31,32]$. Under a constant heating rate, $\beta$, Eq. (1) would be written in the following form:

$\frac{d \alpha}{d T}=\frac{A}{\beta} e^{-E / R T} f(\alpha)$

The Kissinger method [15] is based on the study of the rate equation at the maximum reaction rate. At this point $d^{2} \alpha / d t^{2}$ is equal to zero and, thus, we get from Eq. (1):

$$
\frac{d^{2} \alpha}{d t^{2}}=\left(\frac{E \beta_{m}}{R T_{m}{ }^{2}}+A f^{\prime}\left(\alpha_{m}\right) e^{-E / R T_{m}}\right)\left(\frac{d \alpha}{d t}\right)_{m}=0
$$

where $\mathrm{T}_{m}, \alpha_{m}$ and $(\mathrm{d} \alpha / \mathrm{dt})_{m}$ are the temperature, reacted fraction, and reaction rate at the maximum while $\beta_{m}$ is the value of $\mathrm{dT} / \mathrm{dt}$ at the point in which the maximum reaction rate is reached. $\beta_{m}$ would be constant and equal to $\beta$ only in the case that the experiments were recorded at a constant heating rate as was it formerly assumed by Kissinger. It follows from Eq. (3)

$$
\frac{E \beta_{m}}{R T_{m}^{2}}=-A f^{\prime}\left(\alpha_{m}\right) e^{-E / R T_{m}}
$$

Eq. (4) can be rearranged after taking logarithms into the Kissinger equation:

$$
\ln \left(\frac{\beta_{m}}{T_{m}^{2}}\right)=\ln \left(\frac{A R}{E} f^{\prime}\left(\alpha_{m}\right)\right)-\frac{E}{R T_{m}}
$$

The expressions of the function $f_{(}(\alpha)$ and $f^{\prime}(\alpha)$ for the kinetic models used for describing solid state reactions are shown in table 1 . It is clear that in the case of a first order reaction $(\mathrm{F} 1$ model $), \mathrm{f}^{\prime}(\alpha)=$ 1 and Eq. (5) becomes 


$$
\ln \left(\frac{\beta_{m}}{T_{m}^{2}}\right)=\ln \frac{A R}{E}-\frac{E}{R T_{m}}
$$

Eq. (6) allows to conclude that, provided that a first order reaction is involved and $\left.\beta_{m}\right\rangle 0$, the plot of the left hand side of this equation as a function of $1 / \mathrm{T}$ would lead to a straight line whose slope gives the activation energy, independently of both the heating schedule used for reaching the maximum reaction rate and the value of the reacted fraction, $\alpha_{m}$, at this point.

If the reaction does not follow a first order kinetic model, the slope of the plot of $\ln \beta_{m} / T_{m}^{2}$ versus $1 / T$, according with Eq. (5), would lead to the activation energy only in the case that $\alpha_{m}$ were independent of the heating schedule used. It has been shown in literature [33-41] that if the $\alpha-\mathrm{T}$ plots are recorded under a constant heating rate $\beta$ (i.e.; $\beta_{m}=\beta$ ), the value of $\alpha_{m}$ is nearly independent of the value of the heating rate. Criado an Ortega [36, 37, 39] and Budugreac and Segal [41] have shown that exists a dependence between the values of $\alpha_{m}$ of the different kinetic model quoted in table 1 resulting from linear heating experiments and the actual value of E/RT, although it has been clearly demonstrated that the error in the determination of the activation energy from the Kissinger plot is lower than $5 \%$ for values of E/RT higher than 10 . It is noteworthy to remark that under hyperbolic or logarithmic heating schedules [38] the value of $\alpha_{m}$ is dependent on the kinetic law obeyed by the reaction but independent of the E/RT value.

Under Dynamic Heating Rate (Hi-Res) conditions, heating rate and reaction rate are correlated [13, $14,42]$ by the following equation

$$
\ln (\beta)=\ln \left(\beta_{S}\right)-\text { Rate }\left(\frac{4^{R}}{256}\right)^{S}
$$

being $\beta$ the heating rate at the time $t ; \beta_{\mathrm{S}}$ the starting heating rate selected by the user that is decreasing as far as the Rate (expressed in $\min ^{-1}$ ) increases; $R$ a parameter selected by the user and usually called resolution, and $S$ a sensitivity parameter that generally is fixed at 1 . Eq. (6) can be also written in the form:

$$
\ln (\beta)=\ln \left(\beta_{S}\right)-3.9 .10^{-3} \cdot 4^{R} \frac{d \alpha}{d t}
$$


or

$\ln \frac{d T}{d t}=\ln \left(\beta_{S}\right)-3.9 .10^{-3} \cdot 4^{R} \frac{d \alpha}{d t}$

Salin and Seferis [30] have concluded that the Kissinger method can be extended to the determination of the activation energy from experimental data obtained under the heating schedule expressed by eqn. (7) [or the equivalent equations (7) or (8)]. This method has been often used for the kinetic analysis of experimental data obtained under Hi-Res conditions by a number of authors [26-30]. However, it must be pointed out that Salin and Seferis [12] did not demonstrated if $\alpha_{\mathrm{m}}$ is independent of the experimental parameters selected in the dynamic heating rate algorithm as demanded by the Kissinger method. Thus, the validity of this method must be reanalysed. This is one of the scopes of this work.

\section{Results}

It was mentioned above, that values of $\alpha_{\mathrm{m}}$ should be identical for the different curves to be analyzed by the Kissinger method. We have tried to resolve the system constituted by the differential equations (1), (3) and (9) and we have not found an analytical solution for $\alpha_{m}$, what suggests that this parameter is not independent of the $\beta_{S}$ and $\mathrm{R}$ values selected for recording the $\mathrm{Hi}$ Res experiments. In order to confirm if the values of $\alpha_{m}$ are dependent on the experimental conditions selected for the dynamic heating rate experiments, the set of curves shown in Fig. 1 have been simulated by assuming a F1 kinetic model, dynamic heating rate conditions $\left(\beta_{S}=25 \mathrm{~K} \mathrm{~min}{ }^{-1}\right.$ and $\mathrm{R}=1,4,6$ and 8 , respectively) and the following kinetic parameters: $\mathrm{A}=10^{14} \mathrm{~min}^{-1}, \mathrm{E}=200 \mathrm{~kJ}$ $\mathrm{mol}^{-1}$. These curves have been simulated solving, by numerical integration with the Mathcad software, the system constituted by the differential equations (1) and (9). The values of $\alpha_{m}$ resulting at the different values of $\mathrm{R}$ selected for the simulation are included in Table 2 together with the corresponding ones of $\beta_{m}$ and $\mathrm{T}_{m}$. These results clearly show that values of $\alpha_{\mathrm{m}}$ are very much dependant on the conditions selected for the high resolution experiment. However, we must bear in 
mind that it was concluded in the theoretical section that in the case of first order reactions, Eq. (6) would be accomplished independently of the heating schedule used for reaching the maximum reaction rate and whatever would be the value of the reacted fraction at the maximum. In order to check this assertion, it has been considered of interest to carry out the combined analysis of the $\mathrm{Hi}$ Res results included in table 2 together with those resulting for a set of d $\alpha / \mathrm{dt}-\mathrm{T}$ curves obtained at different constant heating rates. Fig. 2 shows a set of curves simulated at different heating rates for a F1 kinetic model by assuming the same kinetic parameters used for simulating the curves included in Fig. 1. The values of $\alpha_{m}$ and $\mathrm{T}_{m}$ corresponding to these curves are shown in table 2. It can be observed that in this case, contrarily to what occurs in the case of Hi-Res experiments, the value of $\alpha_{m}$ is nearly independent of the heating rate as it is well established in literature. On the other hand, Fig. 3 shows that the plot of the data included in table 2 according with Eq. (6) leads to a straight line with a correlation coefficient equal to 1.000 and an activation energy $\mathrm{E}=200 \mathrm{~kJ} \mathrm{~mol}^{-1}$ in excellent agreement with the theoretical value. These results confirm that the use of the Kissinger method for determining the activation energy of first order reactions from rising temperature experiments does not depend on the profile of the heating schedule used for achieving the maximum reaction rate because a constancy of the value of the reacted fraction at the maximum is not required.

The accurate determination of the activation energy by the Kissinger method for kinetic models different from F1 requires, according to Eq. (5), a identical value for $\alpha$ at the maximum reaction rate, $\alpha_{m}$, for all the analyzed curves. It is well known [33-41] that this requirement is fulfilled under linear heating program but this requirement is not accomplished under Hi-Res heating program as shown in table 2 . Thus, it would be interesting to analyse the influence of the lack of constancy of the reacted fraction at the maximum reaction rate on the activation energy supplied by the Kissinger equation when applied to analysis of Hi-Res results of reactions that follow a kinetic model different from F1. Fig. 4 shows a set of diagrams calculated with the Mathcad software by assuming an A2 kinetic model, an activation energy $\mathrm{E}=200 \mathrm{~kJ} \mathrm{~mol}^{-1}$, a 
preexponential factor $\mathrm{A}=10^{14} \mathrm{~min}^{-1}$ and dynamic heating rate conditions $\left(\beta_{S}=25 \mathrm{~K} \mathrm{~min}{ }^{-1}\right.$ and $\mathrm{R}=1$, 4, 6 and 8, respectively). The values of $\beta_{m}, \alpha_{m}$ and $\mathrm{T}_{m}$ resulting from these curves are included in table 3. It is clear again that the value of the reacted fraction, $\alpha_{m}$, at the maximum is strongly dependant on the parameters $\beta_{s}$ and $\mathrm{R}$ controlling the heating schedule. Fig. 5 shows that the plot of the values of $\ln \left(\beta_{m} / T_{m}^{2}\right)$ taken from table 3 as a function of the corresponding values of $1 / \mathrm{T}_{m}$ does not lead to a good straight line as pointed out by the poor regression coefficient found $(\mathrm{r}=0.9575)$. Moreover, the apparent activation energy $\mathrm{E}=1319.7 \mathrm{~kJ} \mathrm{~mol}^{-1}$ obtained from the slope of this linear plot is considerably higher than the value of $200 \mathrm{~kJ} \mathrm{~mol}^{-1}$ assumed for simulating the curves in Fig. 4. These results suggest that the Kissinger method cannot be extended for determining the activation energy from $\mathrm{Hi}$-Res rising temperature experiments unless that the reaction obeys a F1 kinetic law.

Fig. 6 shows the set of da/dt-T plots simulated by assuming different linear heating rates and the same kinetic model and kinetic parameters used for simulating the Hi-Res curves in Fig. 4. The values of $\mathrm{T}_{m}$ and $\alpha_{m}$ corresponding to these curves are included in table 3 . It can be observed that the value of $\alpha_{m}$ is practically independent of the heating rate as would be expected from linear rising temperature experiments. Thus, $\mathrm{f}^{\prime}(\alpha)$ is constant and, according with Eq. (4), the plot of $\ln \left(\beta / T_{m}^{2}\right)$ versus $1 / \mathrm{T}_{m}$ shown in Fig. 3 leads to a straight line with a regression coefficient $\mathrm{r}=$ 0.99999 whose slope gives an activation energy $\mathrm{E}=199.7 \mathrm{~kJ} \mathrm{~mol}^{-1}$ that matches the value used for the simulations.

\section{Conclusions}

It can be concluded that, unless a first order kinetic law were involved, the Kissinger method cannot be directly applied to the kinetic analysis of rising temperature experiments obtained under any heating schedules without previously checking that the values of reacted fraction at the maxima remain unchanged for all analyzed curves. This condition is fulfilled if the $\alpha-T$ plots are 
recorded under a linear heating rate but not if these curves are obtained with an $H i-R e s$ rising temperature schedule.

\section{Acknowledgement}

Financial support from project TEP-03002 from Junta de Andalucía is acknowledged.

\section{References}

[1] L. A. Perez-Maqueda, P. E. Sanchez-Jimenez and J. M. Criado, Current Topics in Catalysis, (in press).

[2] J. Rouquerol and T. O. Sorensen, in "Sample Controlled Thermal Analysis", edited by T. O. Sorensen and J. Rouquerol (Kluwer, Dordrecht, 2003) p. 1.

[3] J. Rouquerol, J. Therm. Anal. Cal., 72 (2003) 1081.

[4] J. M. Criado, L. A. Perez-Maqueda, M. J. Dianez and P. E. Sanchez-Jimenez, J. Therm. Anal. Cal., 87 (2007) 297.

[5] M. J. Dianez, L. A. Perez-Maqueda and J. M. Criado, Rev. Sci. Instrum., 75 (2004) 2620.

[6] P. A. Barnes, M. J. Tiernan and G. M. B. Parkes, J. Therm. Anal. Calorim., 56 (1999) 733.

[7] S. Bordere, F. Rouquerol, J. Rouquerol, J. Estienne and A. Floreancig, J. Therm. Anal., 36 (1990) 1651.

[8] F. J. Gotor, L. A. Perez-Maqueda, A. Ortega and J. M. Criado, J. Therm. Anal. Calorim., 53 (1998) 389.

[9] L. A. Perez-Maqueda, J. M. Criado and F. I. Gotor, Int. J. Chem. Kin., 34 (2002) 184.

[10] L. A. Perez-Maqueda, A. Ortega and J. M. Criado, Thermochim. Acta, 277 (1996) 165.

[11] M. H. Stacey, Anal. Proc., 22 (1985) 242.

[12] M. J. Tiernan, P. A. Barnes and G. M. B. Parkes, J. Phys. Chem. B, 103 (1999) 338. 
[13] P. S. Gill, S. R. Sauerbrunn and B. S. Crowe, J. Therm. Anal., 38 (1992) 255.

[14] S. Sauerbrunn and P. Gill, Am. Lab., 26 (1994) 29.

[15] H. E. Kissinger, Anal. Chem., 29 (1957) 1702.

[16] L. Abate, I. Blanco, F. A. Bottino, G. Di Pasquale, E. Fabbri, A. Orestano and A. Pollicino, J. Therm. Anal. Cal., 91 (2008) 681.

[17] S. M. Ahmed and M. I. Abd-Elrhaman, J. Therm. Anal. Cal., 91 (2008) 195.

[18] M. V. Borrachero, J. Paya, M. Bonilla and J. Monzo, J. Therm. Anal. Cal., 91 (2008) 503.

[19] A. d'Almeida, D. W. Barreto, V. Calado and J. R. M. d'Almeida, J. Therm. Anal. Cal., 91 (2008) 405.

[20] M. D. Fernandez and M. J. Fernandez, J. Therm. Anal. Cal., 91 (2008) 447.

[21] A. Kropidlowska, A. Rotaru, M. Strankowski, B. Becker and E. Segal, J. Therm. Anal. Cal., $91(2008) 903$.

[22] A. Revesz, J. Therm. Anal. Cal., 91 (2008) 879.

[23] J. M. Salla, X. Fernandez-Francos, X. Ramis, C. Mas, A. Mantecon and A. Serra, J. Therm. Anal. Cal., 91 (2008) 385.

[24] S. Vecchio, L. Campanella, A. Nuccilli and M. Tomassetti, J. Therm. Anal. Cal., 91 (2008) 51.

[25] J. Zhang, Y. Y. Liu, J. L. Zeng, F. Xu, L. X. Sun, W. S. You and Y. Sawada, J. Therm. Anal. Cal., 91 (2008) 861.

[26] C. Gamlin, M. G. Markovic, N. K. Dutta, N. R. Choudhury and J. G. Matisons, J. Therm. Anal. Cal., 59 (2000) 319.

[27] A. J. Gu and G. Z. Liang, J. Appl. Polym. Sci.. 89 (2003) 3594.

[28] B. A. Howell and J. A. Ray, J. Therm. Anal. Cal., 83 (2006) 63.

[29] X. G. Li and M. R. Huang, J. Appl. Polym. Sci., 71 (1999) 565.

[30] I. M. Salin and J. C. Seferis, J. Appl. Polym. Sci., 47 (1993) 847.

[31] J. M. Criado and L. A. Perez-Maqueda, J. Therm. Anal. Cal., 80 (2005) 27. 
[32] J. M. Criado and L. A. Perez Maqueda, in "Sample Controlled Thermal Analysis:

Origin, Goals, Multiple Forms, Applications and Future", edited by O. T. Sorensen and J. Rouquerol (Kluwer, Dordrecht, 2003) p. 55.

[33] J. H. Flynn and L. A. Wall, J. Res.Nat.Bur.Stand. (A), 70 (1960) 487.

[34] H. H. Horowitz and G. Metzger, Anal. Chem., 35 (1963) 1464.

[35] G. Gyulay and E. J. Greenhow, Thermochim. Acta, 6 (1973) 254.

[36] J. M. Criado, R. Garciarojas and J. Morales, Thermochim. Acta, 25 (1978) 257.

[37] J. M. Criado and A. Ortega, J. Non-Cryst. Solids, 87 (1986) 302.

[38] J. M. Criado and A. Ortega, Thermochim. Acta, 103 (1986) 317.

[39] J. M. Criado and A. Ortega, Acta Metal., 35 (1987) 1715.

[40] D. Chen, X. Gao and D. Dollimore, Thermochim. Acta, 215 (1993) 109.

[41] P. Budrugeac and E. Segal, J. Therm. Anal. Cal., 88 (2007) 703.

[42] J. Rouquerol, T. O. Sorensen, P. A. Barnes, E. L. Charsley, E. Fesenko and M. Reading, in "Sample Controlled Thermal Analysis", edited by T. O. Sorensen and J. Rouquerol (Kluwer Academic Publishers, Dordrecht, Netherlands, 2003) p. 16. 


\section{Captions of figures}

Fig. 1. Curves simulated by assuming Hi-Res heating schedule a F1 kinetic model and the following kinetic parameters: $E=200 \mathrm{~kJ} \mathrm{~mol}^{-1} ; A=10^{14} \mathrm{~min}^{-1}$. A value of $\beta_{\mathrm{S}}=50 \mathrm{~K} \mathrm{~min}^{-1}$ and values of the resolution parameter, $R$, equal to $2(\mathrm{a}), 3(\mathrm{~b})$ and $5(\mathrm{c})$, respectively, have been assumed.

Fig. 2. Curves simulated by assuming constant heating rates of 5 (a), 20 (b) and 50 (c) $\mathrm{K} \mathrm{min}^{-1}$, respectively, and the same kinetic model, i.e. F1, and kinetic parameters, i.e. $\mathrm{E}=200 \mathrm{~kJ} \mathrm{~mol}^{-1}$ and $\mathrm{A}=10^{14} \mathrm{~min}^{-1}$, as in Fig. 1.

Fig. 3. Kissinger plot of the values of $\ln \left(\beta_{m} / T_{m}^{2}\right)$ as a function of $10^{3} / \mathrm{T}_{m}$ calculated from table 2 .

Fig. 4. Curves simulated for an A2 kinetic model by assuming the same kinetic parameters of Fig. 1, i.e. $\mathrm{E}=200 \mathrm{~kJ} \mathrm{~mol}^{-1}$ and $\mathrm{A}=10^{14} \mathrm{~min}^{-1}$, and Hi-Res heating with $\beta_{\mathrm{S}}=50$ and resolution parameter, $R$, equal to 2 (a), 3 (b), 4 (c) and $5(\mathrm{~d})$, respectively.

Fig. 5. Kissinger plots of the values of $\ln \left(\beta_{m} / T_{m}^{2}\right)$ as a function of $10^{3} / \mathrm{T}_{m}$ calculated from table 3

Fig. 6. Curves simulated by assuming constant heating rates of 5 (a), 10 (b), 20 (c) and 50 (d) K $\mathrm{min}^{-1}$, respectively, an A2 kinetic model and the same kinetic parameters assumed in Fig. 1, i.e. $\mathrm{E}=$ $200 \mathrm{~kJ} \mathrm{~mol}^{-1}$ and $\mathrm{A}=10^{14} \mathrm{~min}^{-1}$. 
TABLE 1. $f(\alpha)$ kinetic functions and their first derivatives

\begin{tabular}{lcc}
\hline Symbol & $\mathrm{f}(\alpha)$ & $\mathrm{f}^{\prime}(\alpha)$ \\
\hline R2 & $(1-\alpha)^{1 / 2}$ & $\frac{-1}{2(1-\alpha)^{1 / 2}}$ \\
R3 & $(1-\alpha)^{2 / 3}$ & $\frac{-2}{3(1-\alpha)^{1 / 3}}$ \\
F1 & $(1-\alpha)$ & $\frac{n \ln (1-\alpha)+n-1}{[-\ln (1-\alpha)]^{1 / n}}$ \\
An & $n(1-\alpha)[-\ln (1-\alpha)]^{1-1 / n}$ & $\frac{-1}{[\ln (1-\alpha)]^{2}(1-\alpha)}$ \\
D2 & $1 /[-\ln (1-\alpha)]$ & $\frac{1 / 2-(1-\alpha)^{-1 / 3}}{\left[1-(1-\alpha)^{1 / 3}\right]^{2}}$ \\
D3 & $\frac{3(1-\alpha)^{2 / 3}}{2\left[1-(1-\alpha)^{1 / 3}\right]}$ & $\frac{-(1-\alpha)^{-4 / 3}}{2\left[(1-\alpha)^{-1 / 3}-1\right]^{2}}$ \\
D4 & $\frac{3}{2\left[(1-\alpha)^{-1 / 3}-1\right]}$ &
\end{tabular}

Table 2. Values of $\alpha_{m}, \beta_{m}$ and $\mathrm{T}_{m}$ for the sets of curves in figures 1 and 2.

\begin{tabular}{|c|c|c|c|}
\hline conditions & $\boldsymbol{\alpha}_{\mathrm{m}}$ & $\beta_{\mathrm{m}}\left(\mathrm{K} \min ^{-1}\right)$ & $\mathbf{T}_{\mathrm{m}}(\mathbf{K})$ \\
\hline$\beta=5 \mathrm{~K} \mathrm{~min}^{-1}$ & 0.612 & 5 & 714.2 \\
\hline$\beta=20 \mathrm{~K} \mathrm{~min}^{-1}$ & 0.610 & 20 & 743.0 \\
\hline$\beta=50 \mathrm{~K} \mathrm{~min}^{-1}$ & 0.609 & 50 & 763.4 \\
\hline $\begin{array}{l}\beta_{\mathrm{S}}=50 \mathrm{~K} \mathrm{~min}^{-1} \\
\text { Res }=2\end{array}$ & 0.501 & 14.7 & 736.5 \\
\hline $\begin{array}{l}\beta_{\mathrm{S}}=50 \mathrm{~K} \mathrm{~min}^{-1} \\
\mathrm{Res}=3\end{array}$ & 0.433 & 5.5 & 716.2 \\
\hline $\begin{array}{l}\beta_{\mathrm{S}}=50 \mathrm{~K} \mathrm{~min}^{-1} \\
\text { Res }=5\end{array}$ & 0.327 & 0.5 & 671.8 \\
\hline
\end{tabular}


Table 3. Values of $\alpha_{m}, \beta_{m}$ and $\mathrm{T}_{m}$ for the sets of curves in figures 4 and 6.

\begin{tabular}{|l|l|l|l|}
\hline conditions & $\boldsymbol{\alpha}_{\mathbf{m}}$ & $\boldsymbol{\beta}_{\mathbf{m}}\left(\mathrm{K} \mathrm{min}^{-1}\right)$ & $\mathbf{T}_{\mathbf{m}}(\mathbf{K})$ \\
\hline$\beta=5 \mathrm{~K} \mathrm{~min}^{-1}$ & 0.62 & 5 & 715.0 \\
\hline$\beta=10 \mathrm{~K} \mathrm{~min}^{-1}$ & 0.62 & 10 & 729.2 \\
\hline$\beta=20 \mathrm{~K} \mathrm{~min}^{-1}$ & 0.62 & 20 & 743.9 \\
\hline$\beta=50 \mathrm{~K} \mathrm{~min}^{-1}$ & 0.62 & 50 & 764.3 \\
\hline $\begin{array}{l}\beta_{\mathrm{S}}=50 \mathrm{~K} \mathrm{~min}^{-1} \\
\mathrm{ReS}=2\end{array}$ & 0.50 & 5.6 & 737.8 \\
\hline $\begin{array}{l}\beta_{\mathrm{S}}=50 \mathrm{~K} \mathrm{~min}^{-1} \\
\operatorname{Res}^{-1}\end{array}$ & 0.43 & 0.6 & 721.9 \\
\hline $\begin{array}{l}\beta_{\mathrm{S}}=50 \mathrm{~K} \mathrm{~min}^{-1} \\
\operatorname{ReS}=4\end{array}$ & 0.39 & $1.110^{-2}$ & 706.5 \\
\hline $\begin{array}{l}\beta_{\mathrm{S}}=50 \mathrm{~K} \mathrm{~min}^{-1} \\
\text { Res=5 }\end{array}$ & 0.33 & $2.710^{-6}$ & 692.3 \\
\hline
\end{tabular}


Figure 1

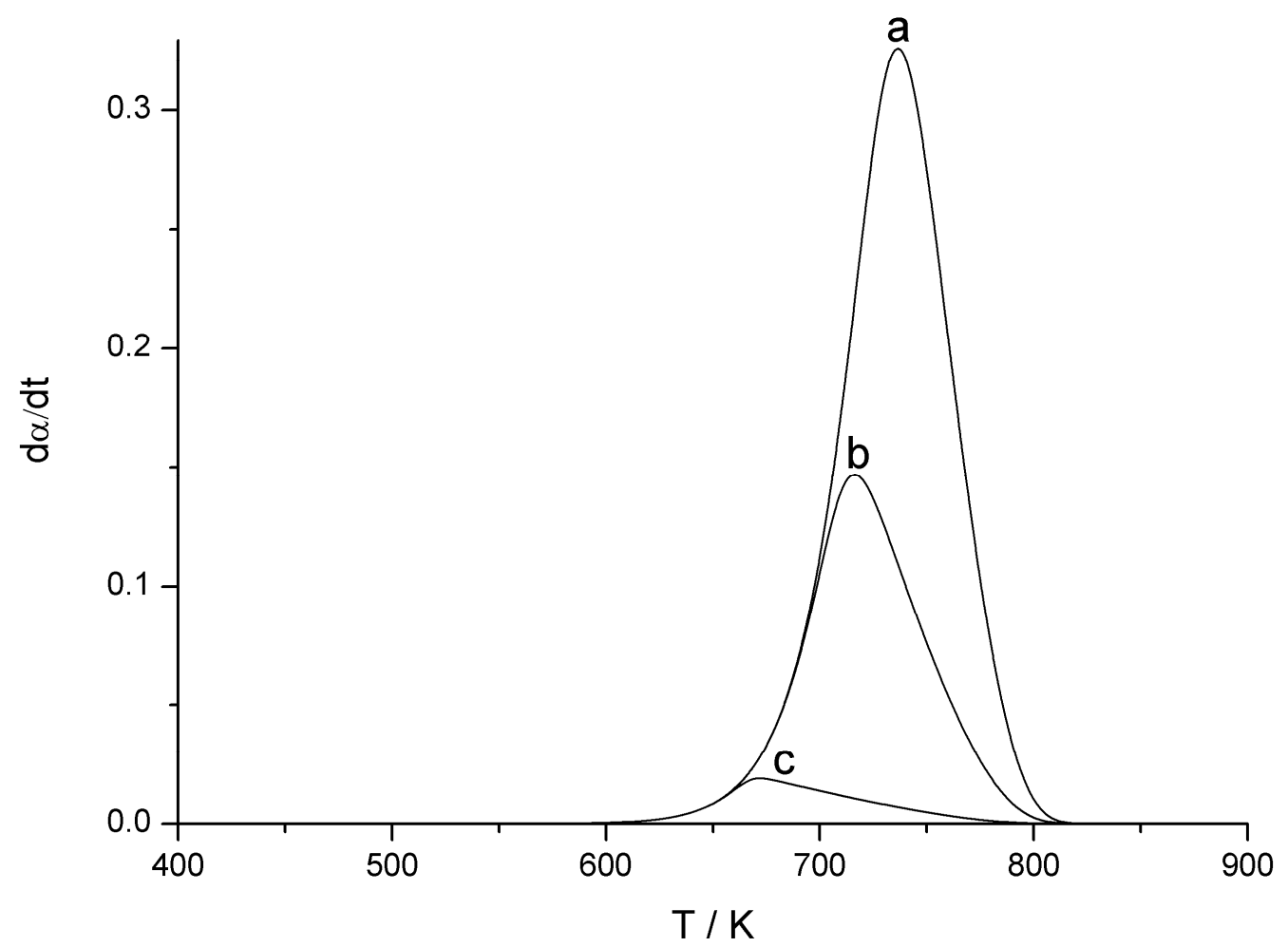


Figure 2

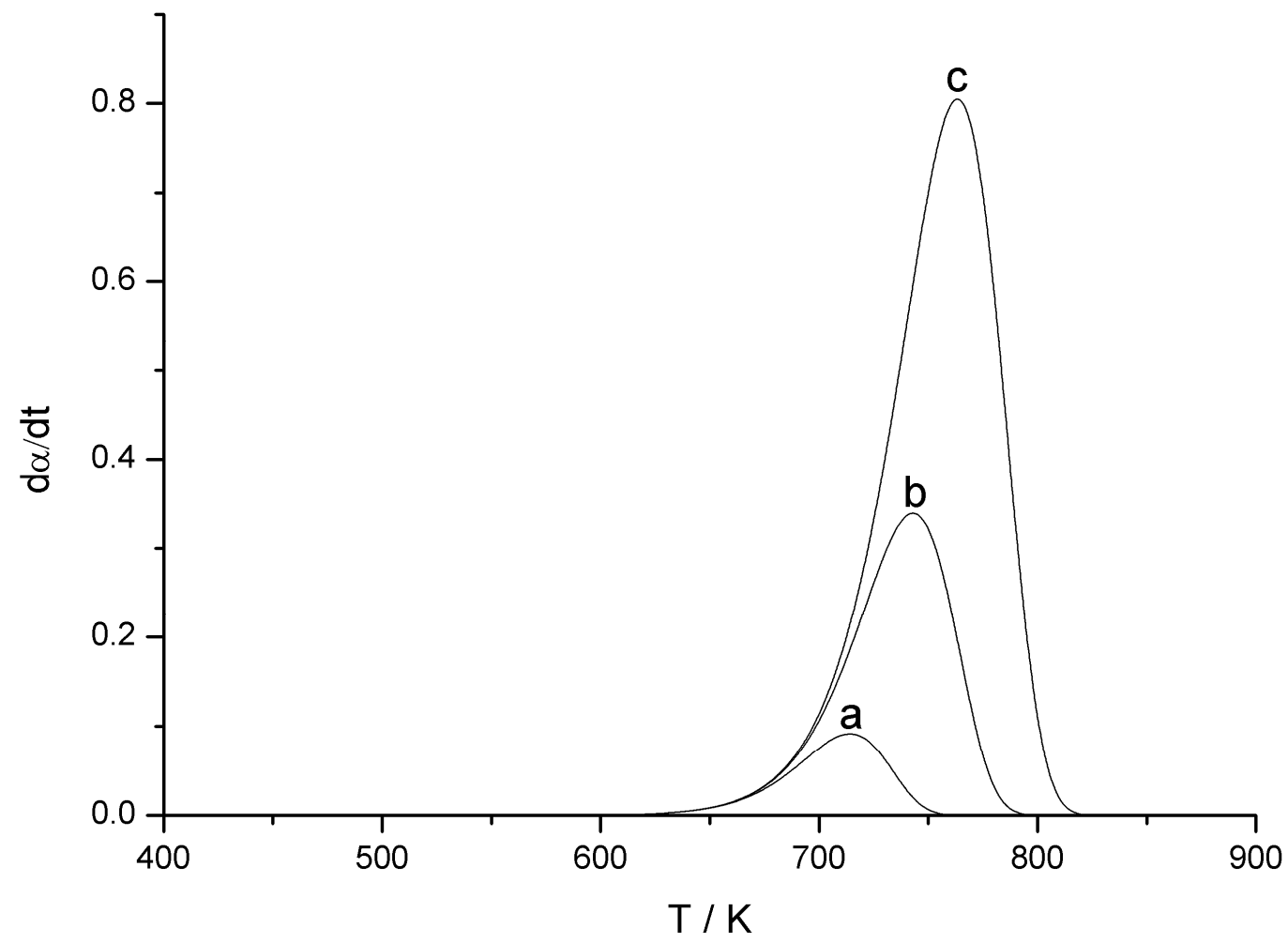


Figure 3

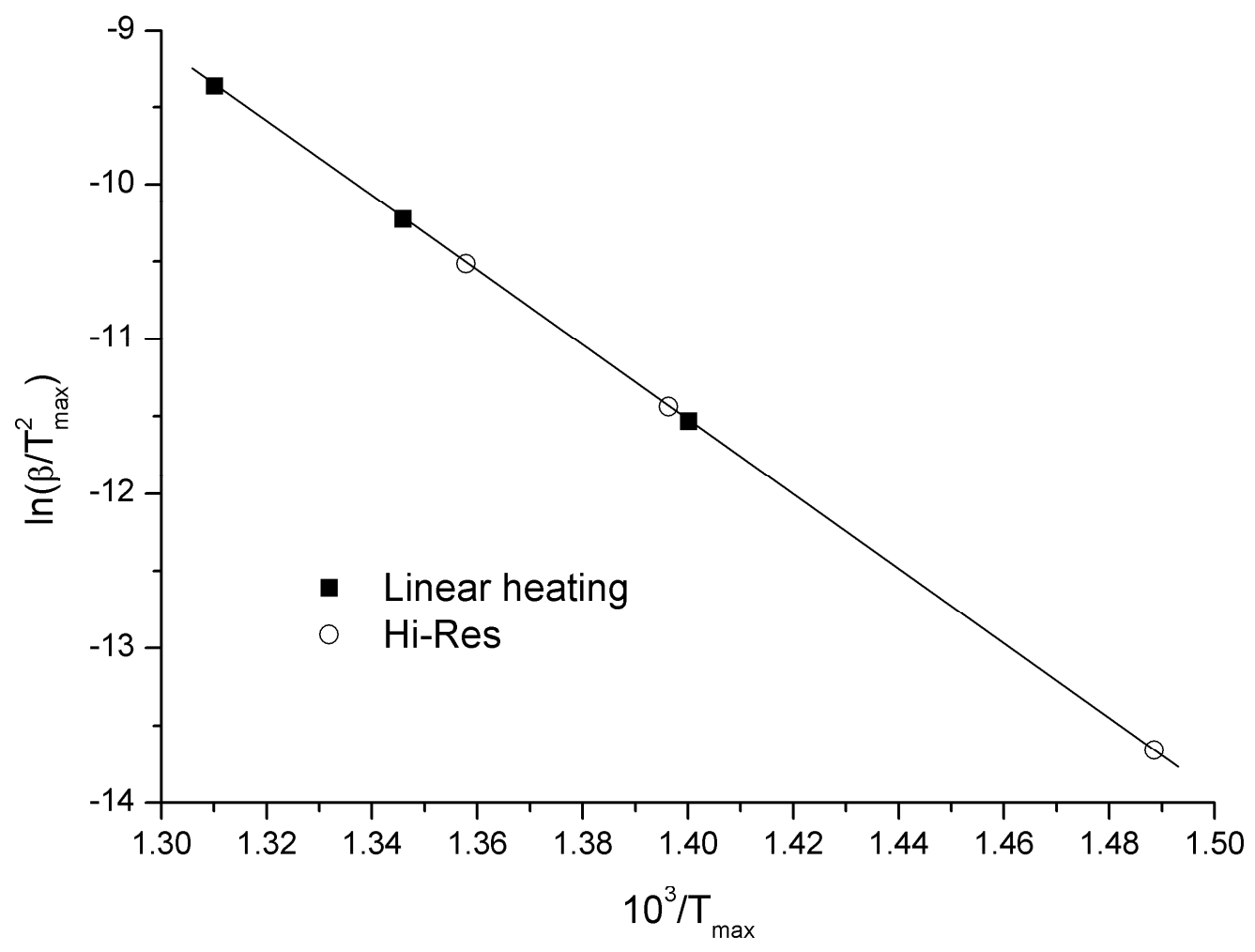


Figure 4

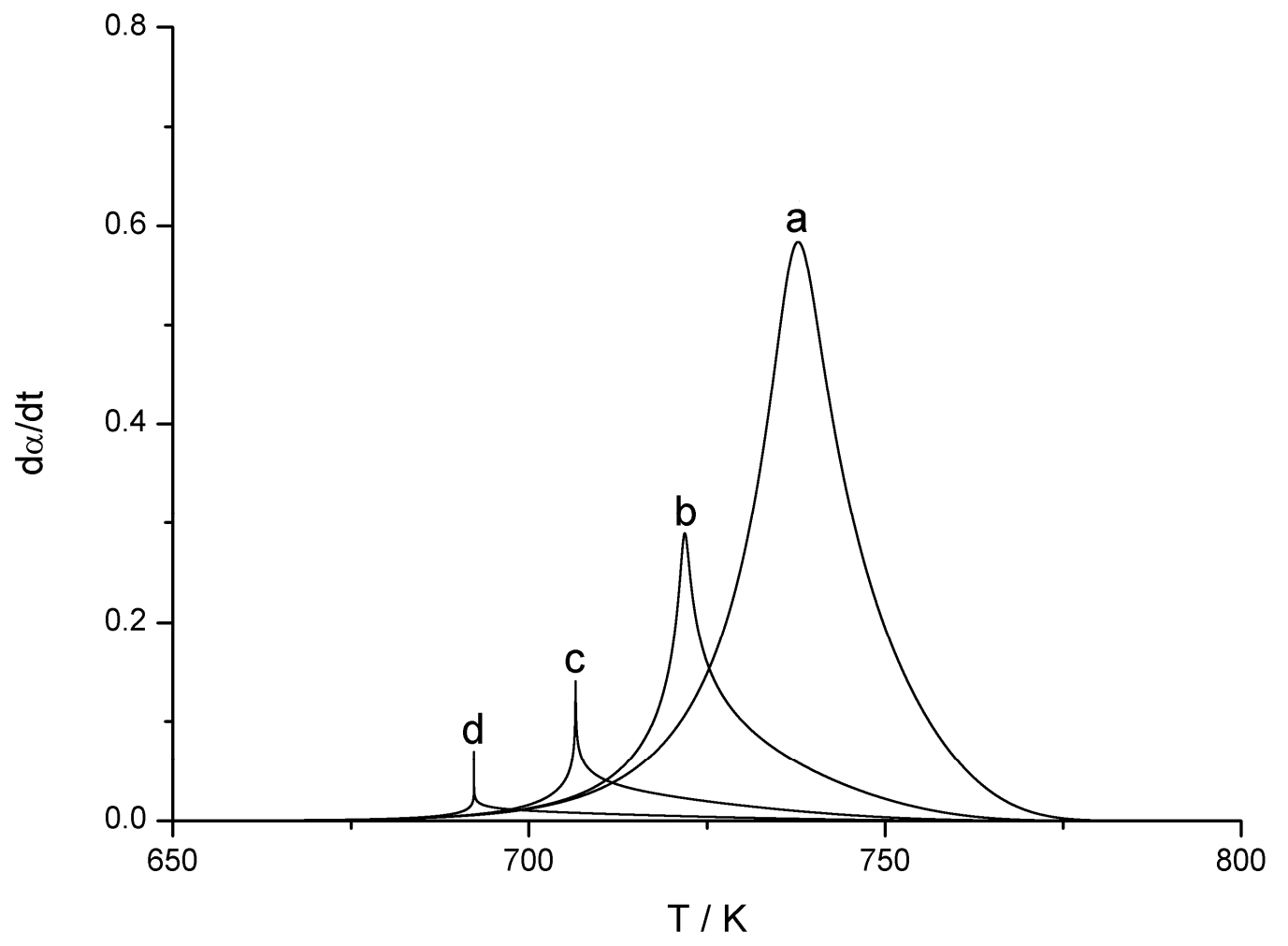


Figure 5

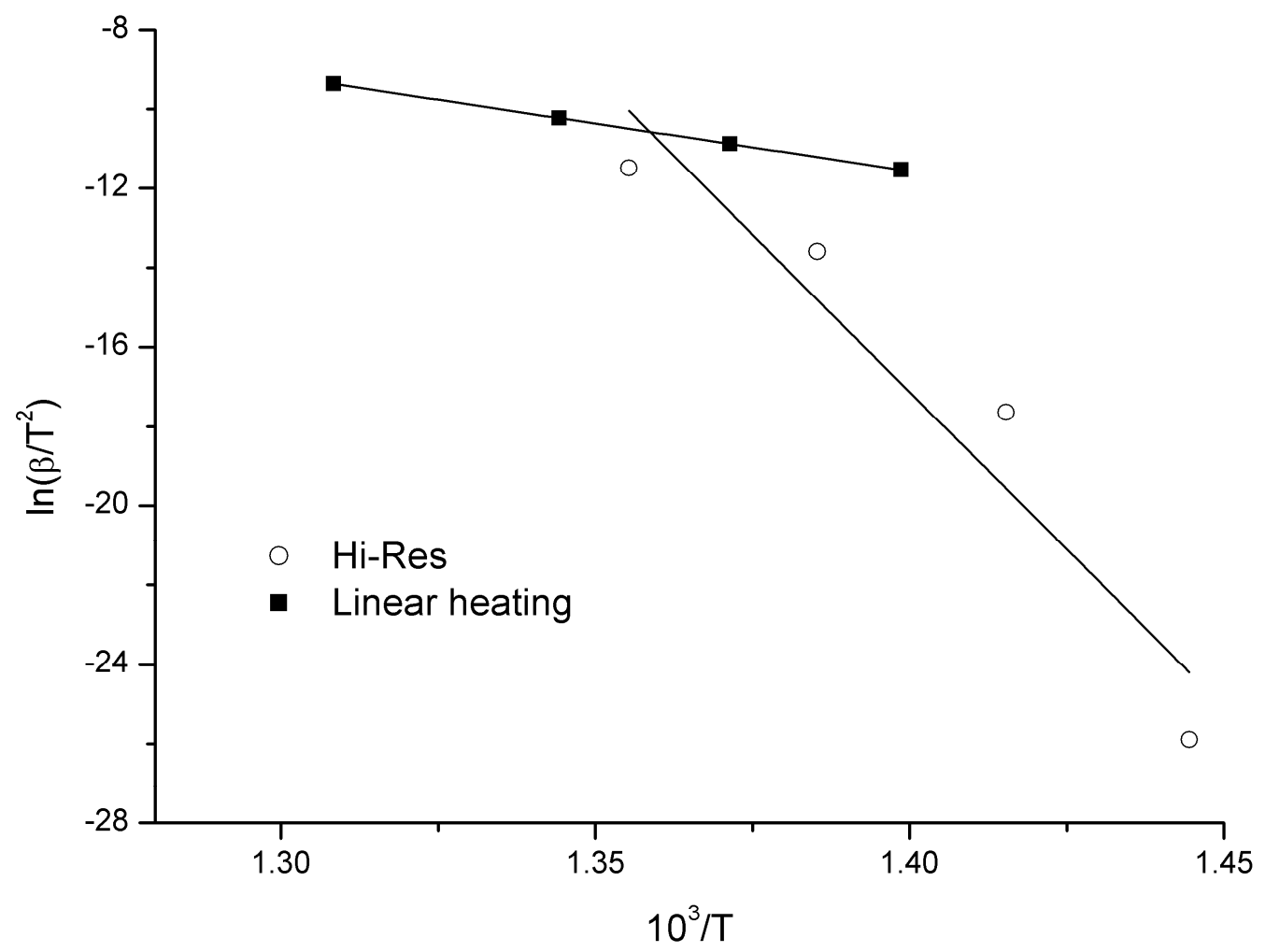


Figure 6

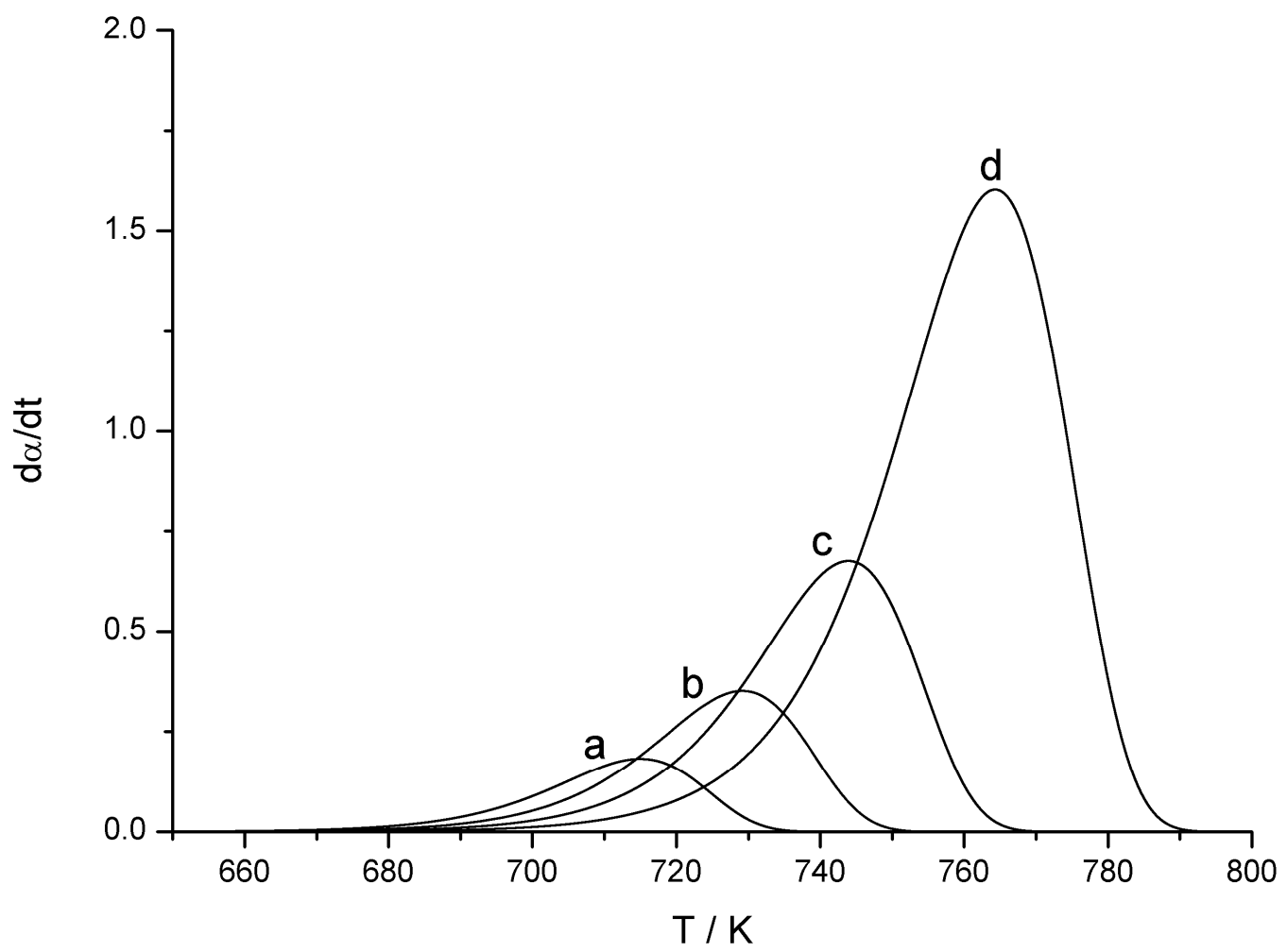

